\title{
THE OPPORTUNITY ANALYSES OF USING THERMOSYPHONS IN COOLING SYSTEMS OF POWER TRANSFORMERS ON THERMAL STATIONS
}

\author{
Atlant Nurpeiis ${ }^{1,}$, and Tatiana Nemova ${ }^{2}$ \\ ${ }^{1}$ National Research Tomsk Polytechnic University, 634050 Tomsk, Russia \\ ${ }^{2}$ Tomsk State Architecture and Civil Engineering, 634003 Tomsk, Russia
}

\begin{abstract}
The opportunity analyses of using the thermosyphons as the main elements in the systems of thermal regime supplying has been conducted under the conditions of their usage in power transformers on thermal stations. Mathematical modeling of jointly proceeding processes of conduction, forced convection and phase transitions (evaporation and condensation) of coolant in the thermosyphon of rectangular cross section has been carried out. The problem of conjugated conductive-convective heat transfer was formulated in dimensionless variables "vorticity/stream function/temperature" and solved by finite difference method. The effect of the heat flux density supplied to the bottom cover of the thermosyphon from a transformer tank on the temperature drop in the steam channel was shown based on the analysis of numerical simulation results (temperature fields and velocities of steam). The parameters of energy-saturated equipment of thermal stations were found to be controlled by an intensification of heat removal from the top cover surface of the thermosyphon.
\end{abstract}

\section{Introduction}

It is known [1] that the most important equipment of thermal stations are the power transformers (PT). And the quality of generated electricity depends on the performance reliability of the power transformers [2]. Generally, the breakdown of the PT leads to large accidents and economical costs to repair [1-3]. During PT working, there are the short-term increases of voltage arising from the normal switching processes in the network or the emergency processes, as well as the pulse wave of the overvoltage arising from lightning atmospheric discharges [4]. One of the main factors affecting the performance reliability of such equipment is their efficient cooling [5-7]. The heat released by the active part is absorbed by the oil and transferred to the heat exchanger for further cooling $[5,8]$. However, the use of additional equipment (pumps) for the oil circulation into the external radiators leads to electricity energy costs. For this reason, it is advisable to analyze the

\footnotetext{
*Corresponding author: nurpeiis atlant@mail.ru
} 
possibility of using self-contained heat transfer devices for cooling of the PT. Closed diphasic thermosyphons (CDTs) [10-11] have proven to be highly reliable, efficient heat transfer heat exchangers due to simplicity of manufacture, the absence of moving parts, regardless of the sources of electricity, etc. For this reason, the study of the application possibility of the CDT as a main element of the PT cooling system is an urgent problem.
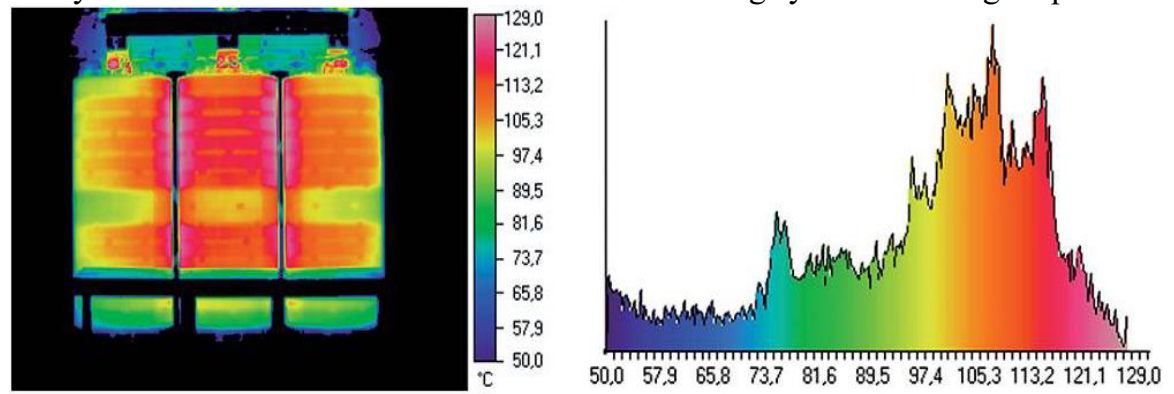

Fig. 1. A reference thermogram obtained for the oil-cooled hermetic transformer TMG "Transformer" with power of $1250 \mathrm{kV} \cdot \mathrm{A}$ and voltage of $10 / 0.4 \mathrm{kV}$ at $100 \%$ capacity [9].

To test the technical condition of PTs, thermal monitoring was used [9]. A processing method that allows to record small changes in temperature on the surface of the tank, caused by small defects in PT, was developed. A reference thermogram (fig.1.) for the oilcooled transformer with power of $1250 \mathrm{kV} \cdot \mathrm{A}$ and voltage of $10 / 0.4 \mathrm{kV}$ at full capacity was obtained [9]. It allows to make a conclusion that the area of a high temperature is located at the top and on the sides of the PT tank. For this reason, the method of transformer tank cooling by a closed diphase thermosyphon was developed. It is proposed to install a vertical thermosyphon on the upper outer surface of the tank.

The aim of the present work is numerical simulation of the thermal regime of the twophase closed thermosyphon under the condition of energy extraction from the power transformer.

\section{Setting of the problem}

The problem of conductive-convective heat transfer was solved in the area presented in fig.2. The closed thermosyphon of rectangular cross section made of copper and partially filled with liquid was under consideration. The energy was supplied to the CDT from the transformer through the surface $y=0,0<x<\left(l_{1}+l_{2}+L+l_{3}+l_{4}\right)$. The outer boundaries of the vertical walls were considered to be insulated. Convective heat transfer with the environment was taken into account on the top horizontal border. Vapors generated at the evaporation of the coolant were considered as viscous incompressible heat-conducting medium that satisfies the Boussinesq approximation [12-13]. The conditions of the equality of temperatures and heat flows were accepted on the boundaries $y=h_{1}, y=\left(h_{1}+h_{2}\right)$, $y=\left(h_{1}+h_{2}+H\right), \quad y=\left(h_{1}+h_{2}+H+h_{3}\right), x=l_{1}, \quad x=\left(l_{1}+l_{2}\right), \quad x=\left(l_{1}+l_{2}+L\right)$, $x=\left(l_{1}+l_{2}+L+l_{3}\right)$. The liquid layer forming due to the condensation of the vapor on the top cover flows into the evaporation zone under the conditions of gravity force. It was suggested that thermal-physical properties of the elements in this system do not depend on the temperature; the thickness of condensate film on the vertical and horizontal walls does not change in time. 


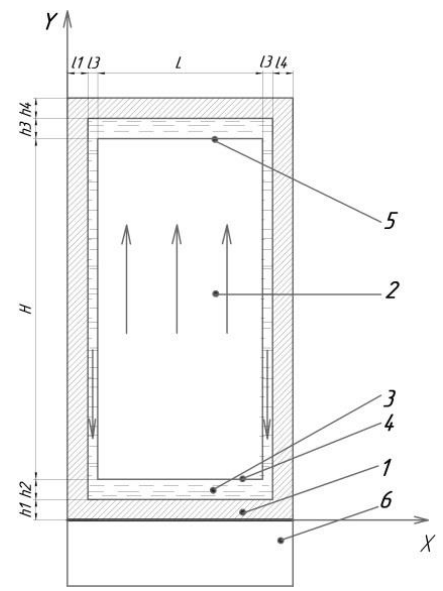

Fig. 2. The area of solution: 1 - metal enclosure; 2 - steam channel; 3 - liquid film; 4 - evaporation surface; 5 - condensation surface; 6 - top wall of the transformer tank. The vertical arrows indicate he direction of the liquid and vapor motion.

Heat transfer in CDT (fig. 2.) within the accepted physical model is described by the Navier-Stokes and energy equations in the converted dimensionless variables, as in [14-16] and have the form:

$$
\begin{aligned}
& \frac{\partial \Omega}{\partial \tau}+\frac{\partial \Psi}{\partial Y} \frac{\partial \Omega}{\partial X}-\frac{\partial \Psi}{\partial X} \frac{\partial \Omega}{\partial Y}=\frac{1}{\operatorname{Re}} \cdot\left(\frac{\partial^{2} \Omega}{\partial X^{2}}+\frac{\partial^{2} \Omega}{\partial Y^{2}}\right), \\
& \frac{\partial^{2} \Psi}{\partial X^{2}}+\frac{\partial^{2} \Psi}{\partial Y^{2}}=-\Omega, \\
& \frac{\partial \Theta_{2}}{\partial \tau}+\frac{\partial \Psi}{\partial Y} \frac{\partial \Theta_{2}}{\partial X}-\frac{\partial \Psi}{\partial X} \frac{\partial \Theta_{2}}{\partial Y}=\frac{1}{\operatorname{Re} \cdot \operatorname{Pr}} \cdot\left(\frac{\partial^{2} \Theta_{2}}{\partial X^{2}}+\frac{\partial^{2} \Theta_{2}}{\partial Y^{2}}\right), \\
& \frac{\partial \Theta_{3}}{\partial F_{3}}=\frac{1}{\operatorname{Re} \cdot \operatorname{Pr}} \cdot\left(\frac{\partial^{2} \Theta_{3}}{\partial X^{2}}+\frac{\partial^{2} \Theta_{3}}{\partial Y^{2}}\right), \\
& \frac{\partial \Theta_{1}}{\partial F O_{1}}=\frac{\partial^{2} \Theta_{1}}{\partial X^{2}}+\frac{\partial^{2} \Theta_{1}}{\partial Y^{2}} . \\
& \text { Initial conditions for equations }(1)-(5): \\
& \Psi(X, Y, 0)=\Omega_{(X, Y, 0)=0,} \\
& \Theta_{1}(X, Y, 0)=\Theta_{2}(X, Y, 0)=\Theta_{3}(X, Y, 0)=0 .
\end{aligned}
$$

Boundary conditions of equations $(1)-(5)$ :

On the outer vertical boundaries: $\frac{\partial \Theta}{\partial X}=0$

On the boundary: $Y=0,0<X<\frac{l_{1}+l_{2}+L+l_{3}+l_{4}}{H}: \frac{\partial \Theta_{1}}{\partial Y}=K i$

On the boundary:

$$
Y=\frac{h_{1}+h_{2}+H+h_{3}+h_{4}}{H}, 0<X<\frac{l_{1}+l_{2}+L+l_{3}+l_{4}}{H}: \frac{\partial \Theta_{1}}{\partial Y}=B i \cdot\left(\Theta_{1}-\Theta_{e}\right)
$$

On the boundary of the coolant evaporation: 


$$
Y=\frac{h_{2}}{H}, \frac{l_{2}}{H}<X<\frac{L}{H}:\left\{\begin{array}{l}
\Theta_{2}=\Theta_{3} \\
\frac{\partial \Theta_{2}}{\partial Y}=\frac{\lambda_{3}}{\lambda_{2}} \cdot \frac{\partial \Theta_{3}}{\partial Y}-Q_{e} \cdot W_{e}
\end{array}\right.
$$

On the boundary of the coolant condensation:

$$
\begin{aligned}
& Y=\frac{h_{1}+h_{2}+H}{H}, \frac{l_{2}}{H}<X<\frac{L}{H}:\left\{\begin{array}{l}
\Theta_{3}=\Theta_{2} \\
\frac{\partial \Theta_{3}}{\partial Y}=\frac{\lambda_{2}}{\lambda_{3}} \cdot \frac{\partial \Theta_{2}}{\partial Y}+Q_{c} \cdot W_{c}
\end{array}\right. \\
& \text { On the interfaces: }\left\{\begin{array}{l}
\Theta_{i}=\Theta_{j}, \\
\frac{\partial \Theta_{i}}{\partial n}=\frac{\lambda_{j}}{\lambda_{i}} \cdot \frac{\partial \Theta_{j}}{\partial n}, \quad \text { где } \begin{array}{l}
i=\overline{1,3} \\
j=\overline{1,3}
\end{array}
\end{array}\right.
\end{aligned}
$$

The following notations are taken: $F o=\frac{a \cdot t_{0}}{H^{2}}-$ Fourier number; Re - Reynolds number; $\operatorname{Pr}=\frac{v}{a}-$ Prandtl number; $B i=\frac{\alpha \cdot H}{\lambda}-$ Biot number; $\alpha-$ heat exchange coefficient, $\frac{\mathrm{W}}{\mathrm{m}^{2} \cdot \mathrm{K}} ; L-$ crosswise size of the steam channel, $\mathrm{m} ; \mathrm{H}$ - height of the steam channel, $\mathrm{m} ; Q_{e}$ - dimensionless analogue of phase-transition heat at evaporation; $Q_{c}-$ dimensionless analogue of phase-transition heat at condensation; $W_{e}-$ dimensionless analogue of the evaporation rate; $W_{c}$ - dimensionless analogue of the condensation rate; $U$, $V$ - dimensionless rates, corresponding to $u, v ; x, y$ - dimensional coordinates, $\mathrm{m} ; X, Y-$ dimensionless coordinates, corresponding to $x, y ; \lambda$-heat conduction coefficient, $\frac{\mathrm{W}}{\mathrm{m} \cdot \mathrm{K}}$; $\tau$ - dimensionless time; $\Theta-$ dimensionless temperature; $\Psi$ - dimensionless analogue of $\psi ; \Omega-$ dimensionless analogue of $\omega$.

The formulated system of equations with nonlinear boundary conditions was solved by finite difference method [17-18]. The flow of condensate film along the vertical walls was modeled as in [19]. The mass rates of evaporation and condensation were calculated according to the formula of Hertz-Knudsen [20]. An iterative algorithm [21-22] developed to solve the problems of conjugated heat transfer in a multiply-connected regions with intensive local heat release was used in this work.

The algorithms and methods of solution used were verified on the model problems of free and forced convection, published in the top-rated journals. In addition, a comparison of the numerical results with the experimental data was obtained [23].

\section{Results and discussion}

Numerical studies of fluid mechanics and heat transfer in the diphase closed thermosyphon under the conditions of energy removal from the top cover of the power transformer was carried out in a typical range of the heat flux variations, corresponding to the operating modes of the oil-cooled PTs [1-3]. The maximum permissible temperatures of the insulation surface of the PTs are limited by $333^{\circ} \mathrm{K}$. At these temperatures, the heat flows to the bottom cover of the CDT equal from $10^{3} \mathrm{~W} / \mathrm{m}^{2}$ to $2 \cdot 10^{3} \mathrm{~W} / \mathrm{m}^{2}$ depending on the conditions of heat transfer. The geometrical characteristics of the CDT were set in accordance with [24]. The dimensionless complexes were adopted in accordance with the test mode of the vapor flow and the specified dimensions of the heat exchanger under 
consideration. The numerical simulation results (temperature field and velocities of vapor) for clarity are presented in dimensional variables (fig. 3). The coordinate axes are set in meters; temperature is in degrees Kelvin.
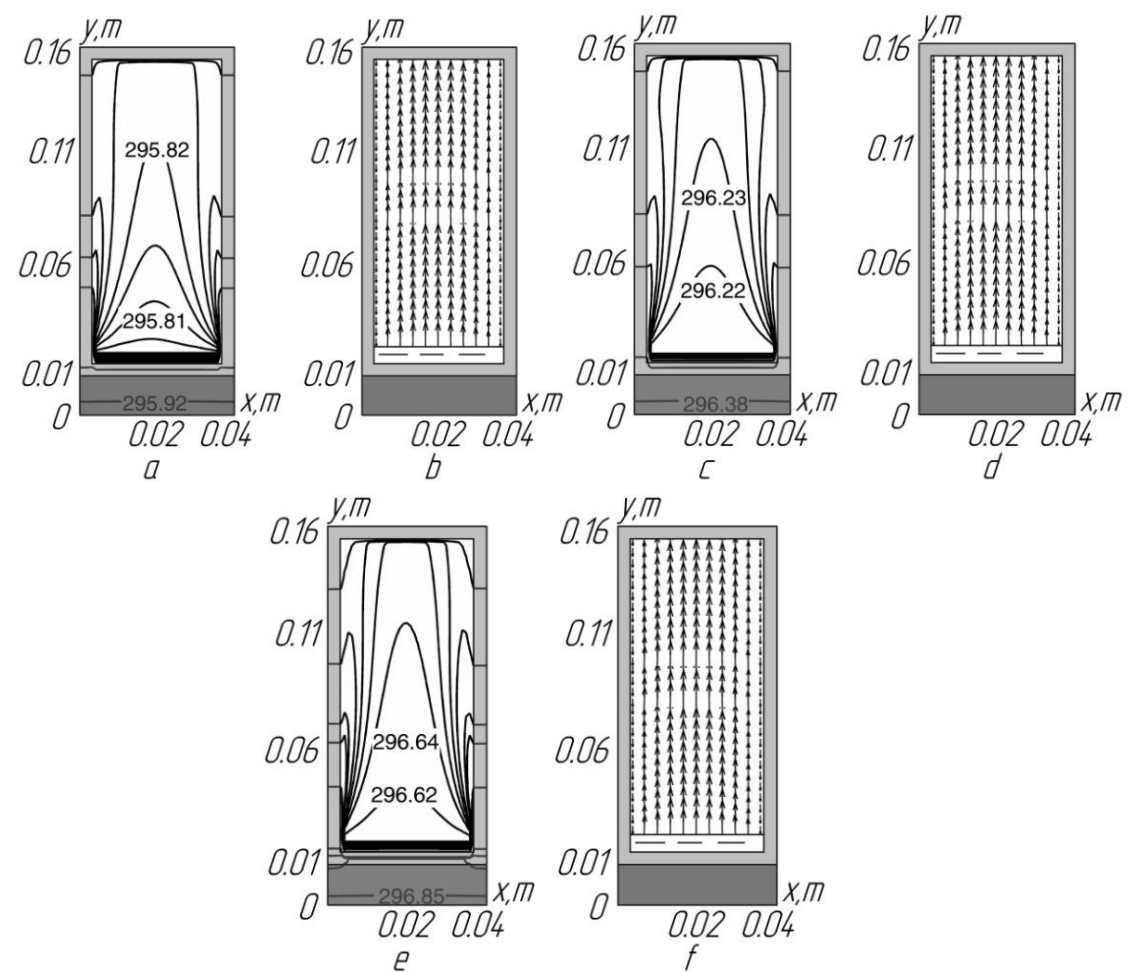

Fig. 3. Isotherms (a, c, e) and fields of vapor velocities (b, d, f) at $\mathrm{Re}=200$ and $\alpha=25 \mathrm{~W} /\left(\mathrm{m}^{2} \mathrm{~K}\right): \mathrm{a}, \mathrm{b}-$ $\mathrm{q}=1000 \mathrm{~W} / \mathrm{m}^{2} ; \mathrm{c}, \mathrm{d}-\mathrm{q}=1500 \mathrm{~W} / \mathrm{m}^{2} ; \mathrm{e}, \mathrm{f}-\mathrm{q}=2000 \mathrm{~W} / \mathrm{m}^{2}$.

Based on the results of numerical simulation analysis, it was found that the increase in the supplied heat flow density $q$ to the bottom cover leads to modification of the temperature fields (fig. 2 a, c, e) in the steam channel of the thermosyphon. At $q=1000$ $\mathrm{W} / \mathrm{m}^{2}$ the bottom cover and the coolant warm in the mode of conduction. It leads to starting of the vaporization process from the lower horizontal "liquid/vapor" interface. Vapor under the pressure gradient starts to move (fig. $3 \mathrm{~b}, \mathrm{~d}, \mathrm{f}$ ) from the evaporation zone to the condensation zone of CDT. The vapor condensates on the boundary of $y=0.147$, $0.003<x<0.037$ (fig. 3). The generated layer of condensate flows along the vertical wall, coming back to the evaporation zone and creating the isolating film between the side wall of the CDT and rising vapor flow. Increase of the heat flow (fig.3 c, e) supplied to the bottom cover of the CDT leads to the increase of the temperature in the steam channel. As a result, the evaporation process becomes more intensive. Isotherms are drawn in the direction of the vapor movement. Extremum of $T$ is observed in the in the section plane of symmetry (fig. $3 \mathrm{a}, \mathrm{c}, \mathrm{e}$ ), which is associated with the choice of the heat removing boundary from the thermosyphon (top cover). The shape of the isotherms in the field of $0<y<0.15$, $0<x<0,01$ is due to the release of heat during the vapor coolant condensation on the boundary of $y=0.147,0.003<x<0.037$.

Figure 4 presents the temperature distribution in $y$ direction in the central section with respect to $\mathrm{x}$. 


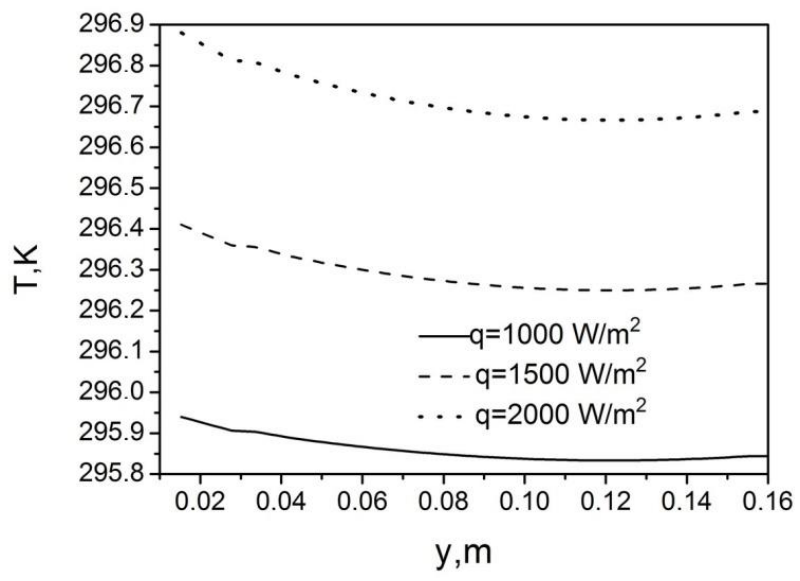

Fig. 4. Temperature distribution along the $y$ axis in the section $x=0.02$.

Based on the analysis of the presented dependences $T=f(y)$ (fig. 4), it can be concluded that the increase of the heat flux density supplied to the bottom horizontal boundary leads to increase of the temperature gradient in the steam channel. The vapor velocity increases due to overheating of the coolant. A small temperature drop can be observed on a horizontal surface $y=0.027,0.003<x<0.037$. It is due to the release of the latent heat of vaporization. Temperature in the vicinity of the horizontal surface $y=0.147,0.003<x<0.037$ increases because of the release of heat at the vapor coolant condensation. Also it should be noted that the increase in heat flux q twice leads to a change of the temperature on the PT tank surface no more than by $1^{\circ} \mathrm{K}$. It illustrates the efficiency of thermosyphon in load conditions corresponding to the thermal regimes of the PTs on the thermal stations.

It is known that the efficiency of thermosyphon cooling system is determined by the heat transfer characteristics of the process in the CDT, namely, by the temperature drop between the upper and lower covers. Analysis of the results allows to conclude that the proposed approach to the study of thermal modes in the CDT permits to predict the variations of the basic characteristics of heat transfer at the heat load changes.

It should also be noted that the results of the performed theoretical studies provide a basis for concluding that it is possible to use the thermosyphon as a regulating system of thermal modes in PTs of the thermal stations in the ranges of load changes from $q=1000$ $\mathrm{W} / \mathrm{m}^{2}$ to $q=2000 \mathrm{~W} / \mathrm{m}^{2}$. Using the presented mathematical model and the method of solving the problem can allow to reduce significantly the number of the experiments on the stage of system designing.

\section{Conclusions}

A new approach to modeling of thermal modes in the CDT, connecting the main thermal and hydrodynamic processes that occur during the operation of such heat exchangers has been proposed. The possibility of PTs coil cooling in thermal stations due to the thermal mode control system working based on the thermosyphons was submitted. The Developed original code can be applied on the stages of designing of power transformers cooling systems on the thermal stations, which is based on the thermosyphons. 


\section{Acknowledgments}

The work was supported by the Russian Federation President's grant (NSH project - 7538.2016.8).

\section{References}

1. V.A. Starshinov, Electrical part of electrical power stations and substations. (Publishing house MEI, Moscow, 2015) [in Russian]

2. V.V. Zhukov, Electrical part of electrical power stations with the gas turbine and combined cycle power plant: a manual for high schools (Publishing house MEI, Moscow, 2015) [in Russian]

3. S.D. Lizunov, Power transformers: (Hand book, ed. by S.D. Lizunova, A.K. Lohanina. Energoizdat, Moscow, 2004) [in Russian]

4. A.M. Golunov. Cooling units of oil power transformers (Energiya, Moscow, 1964) [in Russian]

5. K. Kish, Heating and cooling of transformers (Energiya, Moscow, 1980) [in Russian]

6. K.A., Batischeva, E.G., Orlova, D.V., Feoktistov, EPJ Web Conf. 82 (2015)

7. E.G., Orlova, D.V, Feoktistov, A.G., Islamova, MATEC Web Conf. 23 (2015)

8. E.G., Orlova, G.V., Kuznetsov, MATEC Web Conf. 19 (2014)

9. V.I. Zavidey, V.I. Pechenkin, S.V. Kalanchin, Energoekspert. 6 (2011)

10. M.K., Bezrodnyi, I.L., Pioro, N.O., Kostyuk. Transfer processes in the biphasic thermal siphon systems (Fact, Kiev, 2005) [in Russian]

11. A.E. Nurpeiis, EPJ Web Conf. 76 (2014)

12. Y. Dzhaluriya Natural Convection: Heat and Mass Transfer (Mir, Moscow, 1983 [in Russian])

13. Yu. A., Sokovishyn, O.G., Martynenko, Introduction to the theory of free-convection heat transfer.(Izd-vo Leningrad University, Leningrad, 1982) [in Russian]

14. G.V., Kuznetsov, M.A., Sheremet, Thermophys. Aeromech. 16, 1 (2009)

15. G.V., Kuznetsov, M.A., Sheremet, Russ. Microelectron 37, 2 (2008)

16. A.A. Samarsky. The theory of difference schemes (Nauka, Moscow, 1977) [in Russian]

17. G.V., Kuznetsov, A.E., Sitnikov. High Temp. (2002)

18. G.V., Kuznetsov, A.E., Sitnikov. Therm. Aeromech. 10, 1 (2003) [in Russian]

19. H., Shabgard, B., Xiao, A., Faghri, R, Gupta, W., Weissman. Int. J. Heat Mass Transf. $70(2014)$

20. A.O. Zhdanova, G.V. Kuznetsov, P.A. Strizhak. JEPT. 87 (2014)

21. G.V., Kuznetsov, P.A., Strizhak. J. Eng. Thermosyph. 18, 2 (2009)

22. G.V., Kuznetsov, P.A., Strizhak. Int. J. Heat Mass Transf. 53, 5-6 (2010)

23. B. Fadhl, L.C. Wrobel, H. Jouhara. Appl. Therm. Eng. 78 (2015)

24. G.V. Kuznetsov, M.A. Al-Ani, M.A. Sheremet. J. Eng. Thermosyph. 20, 2 (2011) 